\title{
Miszellen.
}

\section{Der getaufte Löwe.}

Bemerkungen zu Tert. bapt. I7 und Hieron., de vir. ill. 7 .

Der getaufte Löwe, den Hieronymus mit den Wanderungen des Paulus und der Thekla in Verbindung zu bringen scheint, soll, wenn eine neuerdings vertretene Interpretation im Rechte ist, künftig in der Versenkung verschwinden. Die Sache ist wichtig genug, daß man einen Augenblick dabei verweilt. Des raschen Verständnisses wegen ist nochmaliger Abdruck der fast zum Überdruß zitierten Quellenstellen unumgänglich.

Tertull. bapt. 17: Petulantia autem mulieris, quae usurpavit docere, utique non etiam tinguendi ius sibi pariet, nisi si qua nova bestia evenerit similis pristinae, ut, quemadmodum illa baptismum auferebat, ita aliqua per se eum conferat. quodsi quae Pauli perperam inscripta sunt ${ }^{\mathrm{x}}$ exemplum Theclae ad licentiam mulierum docendi tinguendique defendunt, sciant in Asia presbyterum, qui eam scripturam construxit, quasi titulo Pauli de suo cumulans, convictum atque confessum id se amore Pauli fecisse loco decessisse.

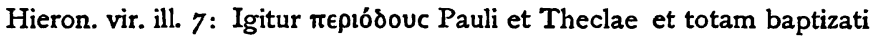
leonis fabulam inter apocryphas scripturas computamus. quale enim est, ut individuus comes apostoli inter ceteras eius res hoc solum ignoraverit! sed et Tertullianus vicinus eorum temporum refert presbyterum quendam in Asia croudactìv apostoli Pauli convictum apud Johannem, quod auctor esset libri, et confessum se hoc Pauli amore fecisse loco excidisse.

In der Einleitung zu seiner Übersetzung der Paulusakten in den von Hennecke herausgegebenen "Neutestamentlichen Apokryphen" glaubt

x So liest Reifferscheid-Wissowa. Gangnejus: quod si quae Pauli perperam scripta sunt, scriptum; Gelenius und Pamelius: quodsi quae Pauli perperam scripta legunt, exemplum; Rigaltius: quodsi quae Paulo perperam adscripta sunt, ad licentiam [?]; Ursinus: quod si quae Paulo perperam adscripta sunt, scriptum; Öhler: quodsi quae Pauli perperam scripta sunt exemplum. Bei all diesen Varianten vermißt man das Subjekt zu sciant. Es ist daher verführerisch, mit Carl Schmidt (Acta Pauli S. 153) zu lesen: quodsi qui Pauli perperam inscripta legunt. 
Ernst Rolffs behaupten zu dürfen, daß Hieronymus den getauften Löwen, von dem in den Thekla-Akten nichts berichtet ist, aus dem von ihm falsch verstandenen Tertulliantexte herausgelesen habe. Er schreibt (S. 358f.): "Hieronymus ist darauf [auf den getauften Löwen] ${ }^{3}$ gekommen durch das Mi@verständnis einer echt tertullianischen Ironie, der[?] a. a. $O$. [bapt. 17] schreibt: ,Die Anmaßung der Frau, die zu lehren beansprucht, wird natürlich nicht auch das Recht zu taufen sich aneignen, es sei denn, eine neue Bestie träte auf, der früheren ähnlich, daG, wie jene (d. h. die Frau, während Hieronymus die Bestie versteht), die Taufe (d. h. das Recht zu taufen, mit Beziehung auf A. Th. 34, wogegen Hieronymus an das Getauftwerden denkt) erlangte, so jede beliebige sie aus eigener Vollmacht übernimmt.' Dieses Mi@verständnis hat die scharfe Zensur des Hieronymus um ihre Wirkung gebracht; da man in den A. Th. von einem. "getauften Löwen" nichts las, so bezog man sein Urteil auf irgendwelche unbekannte Akten, ohne sich dadurch in der Benutzung der beliebten Legende stören $z$ lassen."

$\mathrm{Da}$ Hieronymus flüchtig war, bestreitet niemand. Aber ehe man ihn eines so völligen Mi@verständnisses eines in seiner eigenen Schriftsprache geschriebenen Satzes beschuldigt, sollte man sich's mindestens zweimal überlegen. Zumal wenn dieser Satz, wie sich zeigen wird, keine sonderlichen Schwierigkeiten bietet. Der Irrende ist in diesem Falle ohne Zweifel der Zensor. Unrichtig ist schon seine Übersetzung des utique, das niemals "natürlich" heißt, sondern ,jedenfalls" „unter allen Umständen“, und dessen Sinn an unserer Stelle am besten in der Umschreibung zu Tage tritt: ${ }^{2}$ „wenn auch das Weib sich die Lehre angemaßt hat, so folgt daraus jedenfalls nicht, dab es auch das Recht zu taufen beanspruchen wird." Schlimmer, weil folgenreicher, ist das Mi@verständnis des Nebensatzes. Man scheint freilich gar nicht fehlgehen zu können, da sich die Übersetzung ungezwungen und von selbst bietet: „es sei denn, daß ein Untier aufträte jenem früheren ähnlich, so dab, wie jenes die Taufe davontrug, so irgend eines von sich aus sie übertrüge." Die Beziehung des illa auf bestia ist unumgänglich, und ebenso in die Augen springend die Gegenüberstellung von illa-aliqua und auferre-conferre; auferre baptismum kann niemals hei@en: die Taufe erlangen, vollends nicht das Recht zu taufen erlangen: denn auferre $=$ davontragen wird niemals

Eckige Klammern von, mir.

2 Herr Kollege Wissowr in Halle, dem ich die Stelle, um sicher zu gehen, vorlegte, hatte die Güte, mir seine mit der meinigen übereinstimmende Auffassung mitzuteilen. Die Umschreibung stammt von ihm. 
anders als im Sinn von „wegschaffen" mit all seinen Beziehungen bis zum rauben und stehlen gebraucht. Der Sinn der Stelle kann nur der sein, dab irgend wann einmal ein Untier aufgetreten ist, das die Taufe weggeschafft, bei Seite geschafft, geraubt, gestohlen, vernichtet hat. Als Antitypos dazu kommt nun, meint Tertullian, womöglich (hier liegt der Sarkasmus) eines, das selber taufen will. Dieses Untier ist dann, wenig höflich, das Weib:

Aber was ist denn das für eine pristina bestia, die auferebat baptismum? Wir brauchen nicht weit $z u$ suchen, um unsere philologische Interpretation sachlich bestätigt $\mathrm{zu}$ finden. Gleich der Eingang von de baptismo verhilft uns dazu. Es hei t $_{\text {in }}$ Kap. I: . . nuper conversata. istic quaedam de Gaiana haeresi vipera venenatissima doctrina sua plerosque rapuit, imprimis baptismum destruens. plane secundum naturam suam. nam fere viperae et aspides ipsique reguli serpentes arida et inaquosa sectantur. sed nos pisciculi secundum ỉx $\theta u ́ v$ nostrum Jesum Christum in aqua nascimur nec aliter quam in aqua permanendo salvi sumus. itaque illa monstrosissima, cui nec integrae quidem docendi jus erat, optime norat pisciculos nećare de aqua auferens. Eine Übersetzung dieser Stelle erübrigt sich für unseren Zweck. Es liegt ja auf der Hand, was sie besagen will. Ein Frauenzimmer aus der Sekte des Gajus ${ }^{x}$ ist in Karthago gegen die Wassertaufe aufgetreten. Sie hat die Taufe zerstört, vernichtet. Sie hat es verstanden, die Fischlein zu töten, indem sie sie aus dem Wasser herausnahm, wegschaffte; baptismum destruens - baptismum auferebat: hier haben wir unsere bestia pristina.

Die Sache ist so einfach, daß ein ungeduldiger Leser die lange Auseinandersetzung verübeln möchte. Ich würde auch nicht so lange dabei verweilt haben, hätte nicht Rolff' Übersetzung bereits Unheil angerichtet. Carl Schmidt schreibt in den "Acta Pauli“, nachdem er die Löwen-Frage erörtert hat, zusammenfassend (S. 154): „Aber dies alles sind nur subjektive Erwägungen, so lange der Nachweis nicht erbracht ist, woher die so bestimmte Nachricht über den getauften Löwen stammt. Diesen Nachweis hat $\mathrm{m}$. E. Rolffs geliefert, indem er die unmittelbar dem Berichte des Tertullian vorhergehenden Worte herbeigezogen hat: Petulantiae .... conferat. Hieronymus hat einfach [!] bei seiner be-

I Unsere Kenntnis dieser Sekte schöpfen wir nur aus de baptismo. Die älteren Herausgeber korrigierten die Lesart der Ed. princeps: itague in illa in ita Quintilla, indem sie die Natter Tertullians mit der von Epiph.- haer. 29, I genannten montanistischen Prophetin gleichsetzten. Dazu ist keine Veranlassung, und die eben bezeichnete Eigenschaft der Quintilla macht die Gleichsetzung fast unmöglich. 
kannten Flüchtigkeit in der Benutzung seiner Quelle "illa" (d. h. mulier) auf "bestia" (- Löwe [1]) bezogen und statt "taufen" verstanden „getauft werden".

So wird also der getaufte Löwe zu einer Erfindung des Hieronymus. Das ist allerdings sehr „einfach", hält aber, wie wir gesehen haben, der Nachprüfung nicht Stich. Wir haben uns mit unserem Löwen nach wie vor auseinanderzusetzen. $\mathrm{Zu}$ den Enttäuschungen, die uns der in vieler Beziehung so wertvolle koptische Fund gebracht hat, gehört in erster Linie, daß er dieses Rätsel nicht löst. Es ist ja eine Tücke des Schicksals, da in dem Papyrus die uns ohnehin bekannten Stücke der Akten verhältnismäßig gut, die wenig oder gar nicht bekannten schlecht oder gar nicht überliefert worden sind. So wenig wie der redende Löwe (vgl. Commodian, Carm. apol. 627 f.) ist der getaufte aufgetaucht. So wenig wir aber daran zweifeln können, daß der redende Löwe in den Akten gestanden hat - steht doch der redende Hund (Commod. a. a. O. 626) in den Petrus-Akten -, so wenig möchte wenigstens ich daran zweifeln, $\mathrm{da} B$ der getaufte darin stand. Vielleicht läuft er uns doch noch einmal über den Weg. ${ }^{x}$

Gießen.

$$
\text { G. Krüger. }
$$

\section{Die fünf Männer des samaritanischen Weibes.}

In neuerer Zeit hat man das Wort von den fünf Männern als Symbol der samaritanischen Geschichte aufgefabt und zu 2 Reg $17,24 \mathrm{ff}$. insbesondere Josephus, Ant. IX, I4 I 3 zitiert ( $\$ 288$ bei Niese), wo es heißt:

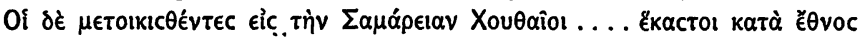

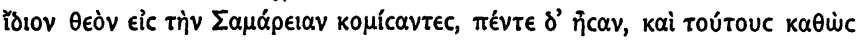

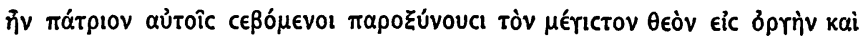

I Ich möchte bei dieser Gelegenheit nicht unerwähnt lassen, daf ich der von Corssen (in dieser Zeitschrift I903, S. 24f.) nach $Z_{a h n}$ vertretenen Anschauung, daß Hieronymus sein Tertullian-Zitat aus der griechischen Bearbeitung von de baptismo entnommen habe, so wenig beizutreten vermag wie Schmidt a. a. O. S. 153. Darüber, daß die Worte presbyterum in Asia ... convictum... et confessum se hoc Pauli amore fecisse loco excidisse die lateinische Bearbeitung vor Augen haben, ist nicht wegzukommen, trotz der auffallenden Abweichung excidisse statt decessisse, zu deren Erklärung

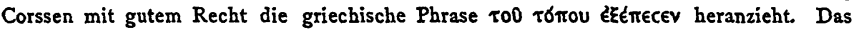
cđoudactíc erklärt sich m. E. zur Genüge aus einem gewissen affektierten (s. Bernoulli, Der Schriftstellerkatalog des Hieronymus; Freib. 1895, 230) Suchen nach einem möglichst „prägnanten“ Ausdruck, oder aus dem auch modernen Schriftstellern geläufigen Bestreben, ein Fremdwort zu benutzen, um eine vielleicht umständliche Erörterung in der Muttersprache durch ein einziges Wort $z u$ ersetzen. Ähnlich ist in cap. 23 (Justin) das $\delta i \alpha-$ трıßác zu beurteilen. 